\title{
AMYGDALOID AND BASAL FOREBRAIN DIRECT CONNECTIONS WITH THE NUCLEUS OF THE SOLITARY TRACT AND THE DORSAL MOTOR NUCLEUS ${ }^{1}$
}

\author{
JAMES S. SCHWABER, ${ }^{2}$ BRUCE S. KAPP, ${ }^{*}$ GERALD A. HIGGINS, AND PETER R. RAPP \\ Departments of Anatomy and Neurobiology and of ${ }^{*}$ Psychology, College of Medicine, University of Vermont, Burlington, \\ Vermont 05405
}

Received August 3, 1981; Revised May 3, 1982; Accepted May 13, 1982

\begin{abstract}
Although the amygdala complex has long been known to exert a profound influence on cardiovascular activity, the neuronal and connectional substrate mediating these influences remains unclear. This paper describes a direct amygdaloid projection to medullary sensory and motor structures involved in cardiovascular regulation, the nucleus of the solitary tract (NTS) and the dorsal motor nucleus (DVN), by the use of autoradiographic anterograde transport and retrograde horseradish peroxidase (HRP) techniques in rabbits. Since all of these structures are highly heterogeneous structurally and functionally, details of the specific areas of the neuronal origin and efferent distribution of the projection were examined in relation to these features and with reference to a cytoarchitectonic description of the relevant forebrain regions in the rabbit. Amygdaloid projections to the NTS and DVN, as determined from HRP experiments, arise from an extensive population of neurons concentrated exclusively within the ipsilateral central nucleus and confined to and distributed throughout a large medial subdivision of this nucleus. Projection neurons, however, also distribute without apparent interruption beyond the amygdala dorsomedially into the sublenticular substantia innominata and the lateral part of the bed nucleus of the stria terminalis and thus delineate a single entity of possible anatomical unity across all three structures, extending rostrocaudally within the basal forebrain as a diagonal band. Descending central nucleus connections, based upon autoradiographic experiments, project heavily and extensively to both the NTS and the DVN. Within both nuclei, the projections have a highly specific distribution pattern, appearing to correspond largely to structural subdivisions, including the dorsomedial, medial, ventrolateral, ventral, and commissural NTS, and to cell group "a," a caudally located dorsomedial region, and peripheral regions of the DVN, some of which appear to be involved in cardiovascuiar regulation.

The existence of such an extensive projection system connecting these specific regions is significant evidence in support of its potential for participation in the amygdaloid expression of cardiovascular influences and has important implications for the cellular analysis of the functional role of these influences.
\end{abstract}

Abundant physiological evidence has accumulated indicating that the amygdala complex exerts a powerful influence on cardiovascular and other autonomic functions (Heinemann et al., 1973; Hilton and Zbrozyna, 1963; Mogenson and Calaresu, 1973). Currently, however, there is a paucity of anatomical information on the amygdaloid

\footnotetext{
${ }^{1}$ This work was supported by United States Public Health Service Grant NS16107, American Heart Association Grant AHA79-1017, and Research Career Development Award MH0018 (B. S. K.). We wish to thank Mary Brent Whipple for assistance with the atlas plates.

${ }^{2}$ To whom correspondence should be addressed at his present address: DuPont Central Research Department, Basic Neuroscience Group, 500 South Ridgeway Avenue, Glenolden, PA 19036.
}

neuronal populations and efferent connections that participate in these influences. Recently, data have been presented which suggest that, within the heterogeneous group of amygdaloid nuclei, the central nucleus of the amygdala may exert a profound influence on cardiovascular activity in the rabbit (Kapp et al., 1978, 1979, 1980). Hence, the present neuroanatomical study was undertaken as part of an effort to determine the systems by which the amygdaloid central nucleus influences cardiovascular activity.

In a preliminary study using the horseradish peroxidase (HRP) technique, we demonstrated that the central nucleus in the rabbit projects directly to the region of the nucleus of the solitary tract and the dorsal motor nucleus of the vagus (Schwaber et al., 1980), findings 
which are consistent with the report of Hopkins and Holstege (1978) that injections of tritiated leucine into the amygdala of the cat result in terminal labeling in these nuclei. This finding of direct connections specifically from the central nucleus to the nucleus of the solitary tract and the dorsal motor nucleus is of particular interest since these latter nuclei play a primary role in cardiovascular and other autonomic regulation as, respectively, sensory and motor structures (e.g., Biscoe and Sampson, 1970; Getz and Sirnes, 1949; Humphrey, 1967; Jordan and Spyer, 1977; Miura and Reis, 1969; Schwaber and Schneiderman, 1975). Thus, the direct connections descending from the central nucleus may mediate central nucleus influences on these cardiovascular and other autonomic functions.

The present study provides essential details of the origin of the present pathway within the central nucleus and of its projections to the nucleus of the solitary tract and dorsal motor nucleus. The neuronal population of the origin of the pathway is described and related to the cytoarchitectonic structure and divisions of the central nucleus. In addition, our preliminary experiments revealed that this efferent neuronal population extends uninterrupted out of the central nucleus well beyond the boundaries of the amygdala into regions of the substantia innominata and bed nucleus of the stria terminalis (Schwaber et al., 1980). Therefore, descriptions also are given of the cytoarchitecture of these structures in order to correlate the nuclear subdivisions with the full distribution of efferent neurons. The pattern of distribution of terminal labeling of the descending central nucleus projections into the nucleus of the solitary tract and the dorsal motor nucleus is described and is of particular significance since both nuclei appear to possess distinct structural subdivisions correlated with the autonomic functions that they subserve (Beckstead and Norgren, 1979; Cohen and Schnall, 1970; Getz and Sirnes, 1949; Kalia and Mesulam, 1980; Mitchell and Warwick, 1955; Schwaber and Cohen, 1978; Loewy and Burton, 1978).

\section{Materials and Methods}

HRP experiments. Injections of HRP (Boehringer, 25 to $50 \%$, in sterile water and, in a few cases, $1 \%$ lysophosphatidylcholine) were made in 42 rabbits into the dorsomedial medulla in a volume of 15 to $100 \mathrm{nl}$ via a $1.0-\mu \mathrm{l}$ Hamilton syringe. In a few cases, electrophoretic injections were made from glass pipettes $(2-\mu \mathrm{A}$ rectangular pulses over 1 to $5 \mathrm{~min}, 20-\mu \mathrm{m}$ tip diameter). The floor of the fourth ventricle was exposed surgically under barbiturate or chloral hydrate anesthesia, and the injection needle or pipette was placed with visual reference to the obex and other relevant landmarks into the border region between the dorsal motor nucleus and the nucleus of the solitary tract. Since both of the nuclei are rostrocaudally elongated cell columns, several injections were made unilaterally at several rostrocaudal levels in order to inject the full extent of the nuclei completely.

Two to 5 days following the injections, the rabbits were killed by anesthetic overdose and perfused with $150 \mathrm{ml}$ of physiological saline followed by 2000 to $3000 \mathrm{ml}$ of 0.5 to $1.0 \%$ paraformaldehyde and $1.25 \%$ glutaraldehyde phosphate-buffered solution over a 30 -min period and $1000 \mathrm{ml}$ of buffered sucrose over a 30 -min period. The brains were sectioned at $40 \mu \mathrm{m}$ in the frontal plane and alternate sections were processed using tetramethylbenzidine or benzidine dihydrochloride as chromogens.

Line drawings of serial sections through the amygdala and basal forebrain were made, and the position of labeled cells was plotted onto the line drawings by reference to landmarks or by the use of a drawing tube (camera lucida). The observed positions of the labeled cells were interpreted with the aid of cytological and topographic observations made from cresyl violet-stained alternate sections and from separate brains prepared as atlases.

The cytoarchitectonic and topographic observations presented here are based on normal rabbit brains embedded in celloidin, sectioned frontally at $90 \mu \mathrm{m}$ in the same plane as the experimental brains, and stained with cresyl violet. Several additional brains were embedded in paraffin, sectioned at 8 to $15 \mu \mathrm{m}$, and stained by the method of Klüver and Barrera (1953) or of Bodian (1937). Photographic and schematic atlases were prepared from this material for interpretation of the experimental observations.

Autoradiographic experiments. The autoradiographic results are based on experiments in which stereotaxic injections of radioactively labeled amino acids were made into the central nucleus of the amygdala or into both the central nucleus and the bed nucleus of the stria terminalis at its ventral border with the sublenticular substantia innominata in 28 barbiturate-anesthetized rabbits. Injections were usually $100 \mathrm{nl}$ but ranged from 50 to $500 \mathrm{nl}$ and consisted of equal parts of $\left[{ }^{3} \mathrm{H}\right]$ proline and $\left[{ }^{3} \mathrm{H}\right]$ leucine $(110 \mathrm{Ci} / \mathrm{mmol}$, Amersham $)$ in a concentration of $50 \mu \mathrm{Ci} / \mu \mathrm{l}$. The usual survival time used was 7 days, although, in some experiments, 1 - and 8-day survival times were used, after which the rabbits were killed by anesthetic overdose and perfused with saline followed by $750 \mathrm{ml}$ of Bouin's fixative. The brains were removed, embedded in paraffin, and sectioned at 10 to $20 \mu \mathrm{m}$. The sections were mounted on slides and coated with Kodak NTB-2 emulsion. Following 6 to 20 weeks exposure at $4^{\circ} \mathrm{C}$, the autoradiographs were developed with Kodak D19 developer, fixed, and stained through the emulsion with cresyl violet.

\section{Results}

Cytoarchitecture and topography of the central nucleus, substantia innominata, and bed nucleus of the stria terminalis

Our experimental observations showed that subcortical forebrain efferents to the nucleus of the solitary tract and dorsal motor nucleus originate in the central nucleus of the amygdala, the substantia innominata, and the bed nucleus of the stria terminalis. Since there is no detailed description of these areas in the rabbit, their topography and cytoarchitecture in this animal will be described briefly in order to provide a basis for interpretation of the results of the HRP and autoradiographic experiments. The terminology used in describing the central nucleus and bed nucleus is based primarily on the recent descriptions presented by Krettek and Price (1978a, b) in the cat and the rat; the terminology used in describing the substantia innominata follows Miodonsky (1967) and 

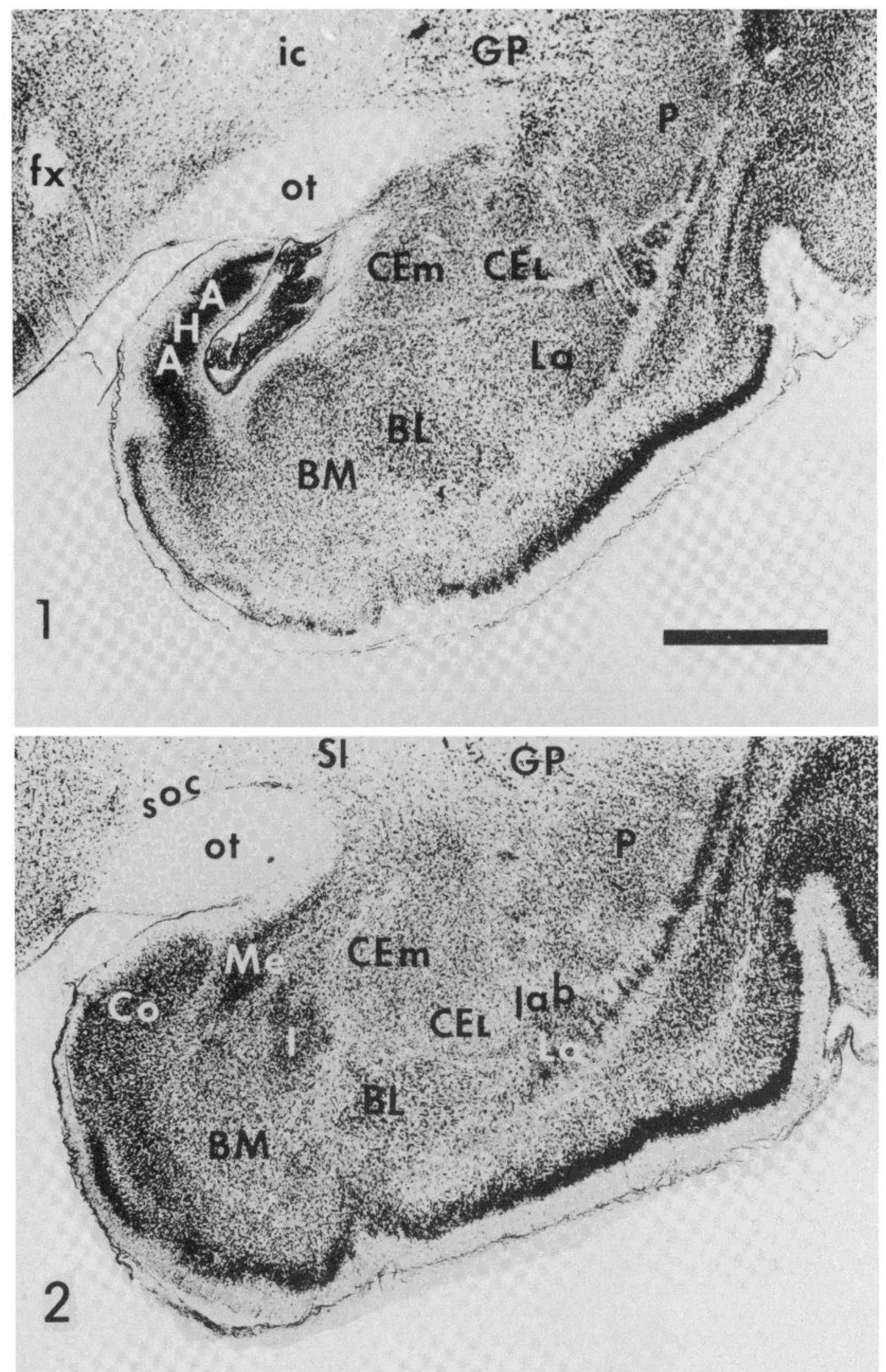

Figures 1 to $4 .^{3}$ Photomicrographs of frontal sections through the amygdala complex and related basal forebrain regions of the rabbit from caudal (Fig. 1) to rostral (Fig. 4). Note the various cytoarchitectonic subdivisions of the amygdala, including the medial and lateral divisions of the central nucleus $\left(C E_{M}\right.$ and $\left.C E_{L}\right)$ and the cellular continuity between the central nucleus, the substantia innominata, and the lateral part of the bed nucleus of the stria terminalis. These are $90-\mu \mathrm{m}$ sections which were stained with cresyl violet. Bars, $1 \mathrm{~mm}$.

${ }^{3}$ The abbreviations used on the figures are: a, subnucleus a of the DVN; AAA, anterior amygdaloid area; ac, anterior commissure; AHA, amygdalohippocampal area; BL, basolateral nucleus of the amygdala; BM, basomedial nucleus of the amygdala; BST, bed nucleus of the stria terminalis; cc, central canal; $\mathrm{CE}$, central nucleus of the amygdala; $\mathrm{CE}_{\mathrm{L}}$, lateral subdivision of the central nucleus of the amygdala; $\mathrm{CE}_{\mathrm{M}}$, medial 

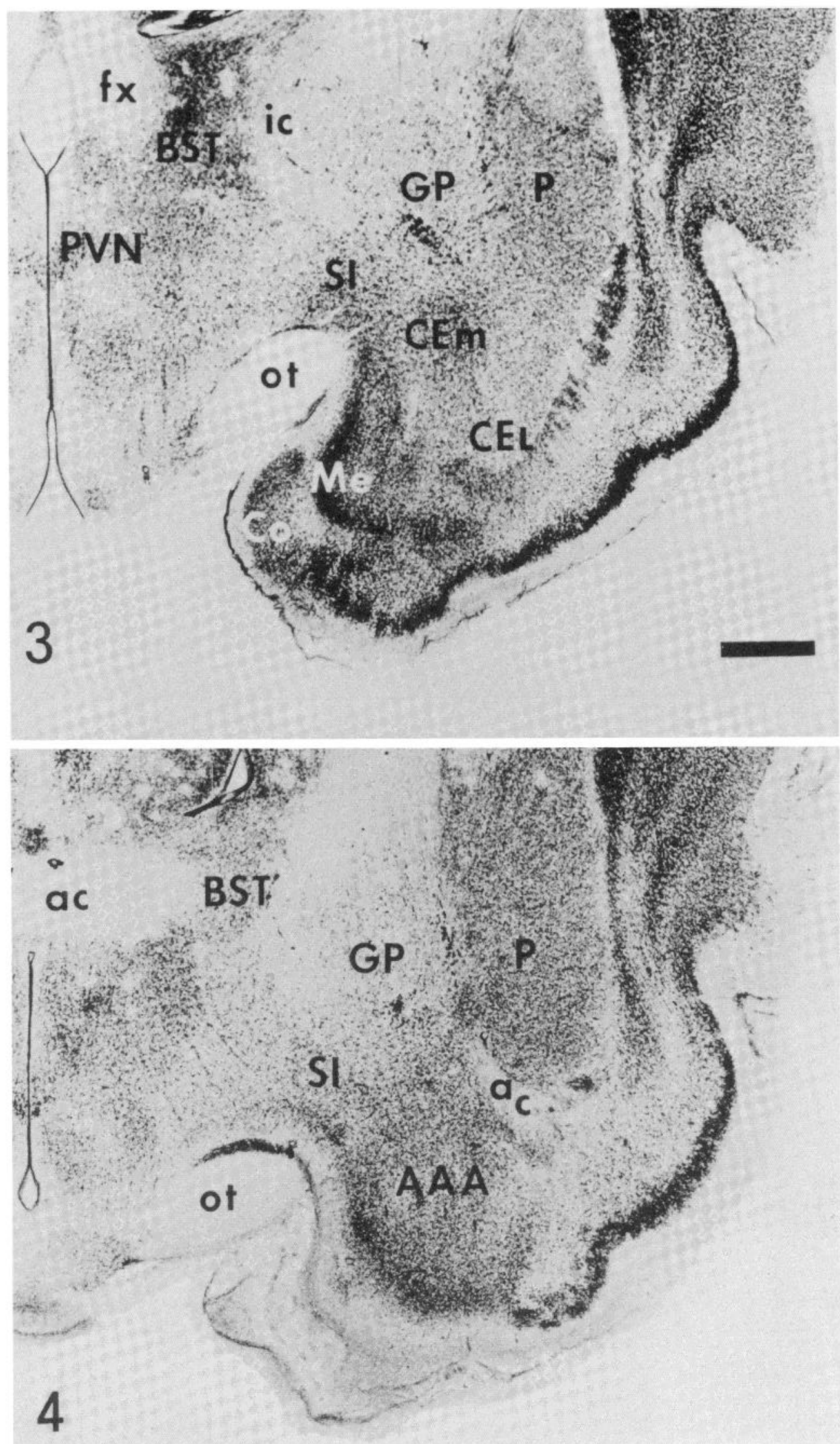

Figures 3 and 4.

subdivision of the central nucleus of the amygdala; Co, cortical nucleus of the amygdala; DMN, dorsal motor nucleus; DVN, dorsal motor nucleus of the vagus; fx, fornix; GP, globus pallidus; I, intercalated cell islands of the amygdala; ic, internal capsule; IO, inferior olive; La, lateral nucleus of the amygdala; lab, longitudinal association bundle of Johnston; LH, lateral hypothalamus; Me, medial nucleus of the amygdala; NA, nucleus ambiguus; NTS, nucleus of the solitary tract; oc, optic chiasm; ot, optic tract; P, putamen; PH, nucleus prepositus hypoglossi; PVN, paraventricular nucleus of the hypothalamus; SI, substantia innominata; soc, supraoptic commissure; SPV, definition; TS, tractus solitarius; V, lateral ventricle; VM, ventromedial nucleus of the hypothalamus; IV, fourth ventricle; VII, facial nerve; XII, hypoglossal nucleus. 
Heimer (1978). Modifications, however, have been made in order to match our observations in the rabbit. As described below, these changes, to some extent, are based on descriptions by Brodal (1947), Fox (1940), Gurdjian (1928), Young (1936), and Wakefield and Hall (1974) of the central nucleus, and by DeOlmos (1972), Jones et al. (1976), and Swanson (1976) of the substantia innominata and bed nucleus.

Central nucleus of the amygdala. The central nucleus of the rabbit is a large, rounded or oval appearing structure that lies medially and dorsally in the amygdala (Figs. 1 to 3). Its ventral and lateral borders are sharply delineated by the fibers of the longitudinal association bundle which, at most rostrocaudal levels, encapsulate the intercalated cell islands and set off the central nucleus from the lateral and basolateral amygdaloid nuclei. Medially, the central nucleus is bordered by the stria terminalis and the intra-amygdaloid portion of its bed nucleus. Dorsally, the central nucleus can be distinguished from the putamen and globus pallidus at caudal levels by the presence of large, darkly staining cells (resembling the so-called basal cell islands of Meynert as defined in the primate by Jones et al., 1976) and by a narrow band of fibers penetrating the posterior portions of the lateral amygdaloid nucleus and passing dorsomedially in the border area. At more rostral levels, the central nucleus is separated from the globus pallidus and putamen by the substantia innominata. This border is not well defined at the rostral pole of the nucleus.

In the rabbit, three subdivisions are apparent within the central nucleus. Medial and lateral subdivisions can be distinguished on the basis of the larger, more heterogeneous, more darkly staining, and more densely packed cells of the medial subdivision. The medial subdivision occupies at least half of the total area of the central nucleus and may be subdivided further into dorsomedial and ventrolateral parts by the delineation of a distinct, dorsomedially located mass of larger, more stellate, and more darkly staining cells (Fig. 2). This larger celled dorsomedial part of the medial subdivision tends to distribute medially at caudal levels (Fig. 1) and to concentrate dorsally at rostral levels (Fig. 3). The lateral subdivision resembles the putamen in cell size and staining density in the rabbit but can be distinguished from the putamen, as in the cat, by its lack of any large cells (Wakefield and Hall, 1974). Fibers oriented in the dorsalventral direction diffusely penetrate much of the central nucleus and are particularly prominent in the ventrolateral part of the medial subdivision.

It should be noted that, although the above description in the rabbit differs from the traditional subdivision of the central nucleus into a small, thin medial subnucleus and a smaller celled, more extensive lateral subdivision in the cat and the rat (Brodal, 1947; Krettek and Price, 1978a; Wakefield and Hall, 1974), it is possible that the traditional medial subdivision may correspond to the present dorsomedial part of the medial subdivision in the rabbit.

Substantia innominata. The substantia innominata (Figs. 2 to 4 ) is an extensive, loosely defined area that extends medially and rostrally from the amygdala into the area ventral to the anterior commissure, extending rostrally to the deep multiform layer of the olfactory tubercle. Within this diffuse area, a subdivision recently has been recognized in the rat between the caudal part of the substantia innominata primarily containing medium sized neurons and the rostrolateral part characterized by large neurons similar to those of the globus pallidus (Heimer, 1978). The more caudal, "sublenticular" (Miodonsky, 1967) part of the substantia innominata is also readily distinguishable in the rabbit as a region extending diagonally along the ventral border of the globus pallidus and merging with the bed nucleus of the stria terminalis rostromedially and with the central nucleus laterocaudally (Fig. 3). Caudally, the substantia innominata first appears as a heterogeneous zone located between the central nucleus ventrally and the globus pallidus and putamen dorsally; in the lateral-to-medial direction, it extends from the longitudinal association bundle adjacent to the lateral amygdaloid nucleus to the dorsal aspect of the optic tract. More rostrally, as the internal capsule moves dorsally from the optic tract, the substantia innominata extends medially along the border of the globus pallidus and internal capsule and then expands and enlarges medially in the region dorsal to the optic tract and ventral to the anterior commissure. Medially, it merges with the preoptic/anterior hypothalamic area and, just caudal to the anterior commissure, with the bed nucleus of the stria terminalis.

The sublenticular substantia innominata in the rabbit is composed principally of medium sized neurons scattered among fibers streaming dorsomedially and rostrally out of the central nucleus and has been described in the rat as a "bed nucleus" for these fibers as they form a branch of the ventral amygdalofugal system (i.e., the compact division of the longitudinal association bundle of Johnston (DeOlmos, 1972)). In addition, also present within the substantia innominata in the rabbit, particularly along the ventral border of the globus pallidus and putamen, are numerous clusters of large, deeply staining, multipolar neurons. These large cells are distinct from globus pallidus cells and may correspond to the cell island of the so-called basal nucleus of Meynert as described in the primate (Jones et al., 1976).

Bed nucleus of the stria terminalis. In the rabbit, a well developed bed nucleus (Figs. 3 and 4), which can be subdivided into lateral and medial parts, is apparent within the components of the stria terminalis at the level of the anterior commissure. The lateral division is composed of loosely packed, elongated cells that are scattered fibers of the stria adjacent to the internal capsule and ventral to the lateral ventricle. This division reaches its greatest extent lateral to the decussation of the anterior commissure, narrows caudally as the fornix begins its descent, and extends ventrally and medially beneath the anterior commissure to merge with the sublenticular substantia innominata. The medial subdivision of the bed nucleus can be distinguished by its smaller, more densely packed, and more deeply staining cells. Although some of its cells extend supracommissurally around and dorsal to the anterior commissure, the medial subdivision is most distinct more caudally, lying as a dense mass of 
cells on the lateral or (more rostrally) ventrolateral border of the fornix which is caudal to the anterior commissure and dorsal to the anterior hypothalamic area and the sublenticular substantia innominata.

\section{HRP results}

Location and extent of amygdaloid and basal forebrain efferents projecting to the dorsal motor nucleus and the nucleus of the solitary tract. The full extent of the amygdaloid, substantia innominata, and bed nucleus origin of the direct pathway to the solitary nucleus and vagal motor complex will be defined by reference to experiments in which injections of HRP were made at multiple points along the rostrocaudal lengths of the dorsal motor nucleus and the nucleus of the solitary tract. Due to the number of injections and the small dimensions of the target nuclei, one or more of the HRP injections usually spread beyond the boundaries of the nuclei. The extent of the injection sites, however, has been interpreted cautiously in terms of the possible involvement of other medullary targets of amygdaloid projections revealed by the results of the autoradiographic experiments described in the present report (particularly the adjacent tegmentum). Furthermore, control injections into adjacent regions, except the ventrolaterally adjacent tegmentum which has been identified as the recipient of central nucleus projections by the autoradiographic experiments, produced negative results with respect to labeled cells in the amygdala and basal forebrain. There were inevitable differences in the size and location of the multiple injections. Consequently, there was some variability across cases in the number of labeled neurons and in the distribution of labeled cells.

The region described below contained labeled cells following large injections $(50 \mathrm{nl})$ centered in and including much of the length of the nucleus tractus solitarius/ dorsal motor nucleus. There appeared to be more abundant cell labeling in cases using lysophosphatidylcholine in the HRP solution, in cases with longer survival times, and in cases using chloral hydrate anesthesia.

Following multiple HRP injections into the nucleus of the solitary tract and dorsal motor nucleus, retrogradely labeled cells within the amygdala occurred only in the ipsilateral central nucleus. In a single case involving large injections of HRP with lysophosphatidylcholine, a few labeled cells were present in the contralateral central nucleus. Cell labeling following larger injections was abundant, distributed throughout a large area of the central nucleus, and present at all levels from the caudal pole of the central nucleus to its rostral limits.

Retrograde labeling within the central nucleus was confined to the large medial subdivision of the nucleus as defined above, with the smaller celled lateral subdivision remaining free of labeled cells. The regions in Figure 5 delimited by dots representing the positions of labeled cells can be seen to outline, at matching rostrocaudal levels, the region of the medial subdivision (Figs. 1 to 3). From the caudal to rostral levels, the area containing labeled cells follows the medial subdivision as it expands laterally from the lateral border of the stria terminalis and then concentrates more dorsally within the central nucleus. Retrogradely labeled neurons generally appeared to be medium sized, spindle-shaped or stellate cells of the type characteristic of the medial subdivision.

The population of HRP-labeled cells within the central nucleus ordinarily appeared to divide into a group of more heavily labeled, larger cells and a more ventral and lateral group of somewhat more lightly labeled, more diffusely organized cells (Fig. 5, $C, D$, and $E$ ). These groups correspond to the structurally distinct dorsomedial and ventrolateral parts of the medial subdivision. In cases in which reduced numbers of labeled neurons occurred, HRP-positive cells in the central nucleus were located preferentially or exclusively within the dorsomedial part.

At rostral levels of the central nucleus, retrogradely labeled neurons within the central nucleus were found to be continuous with other HRP-labeled cells located out-

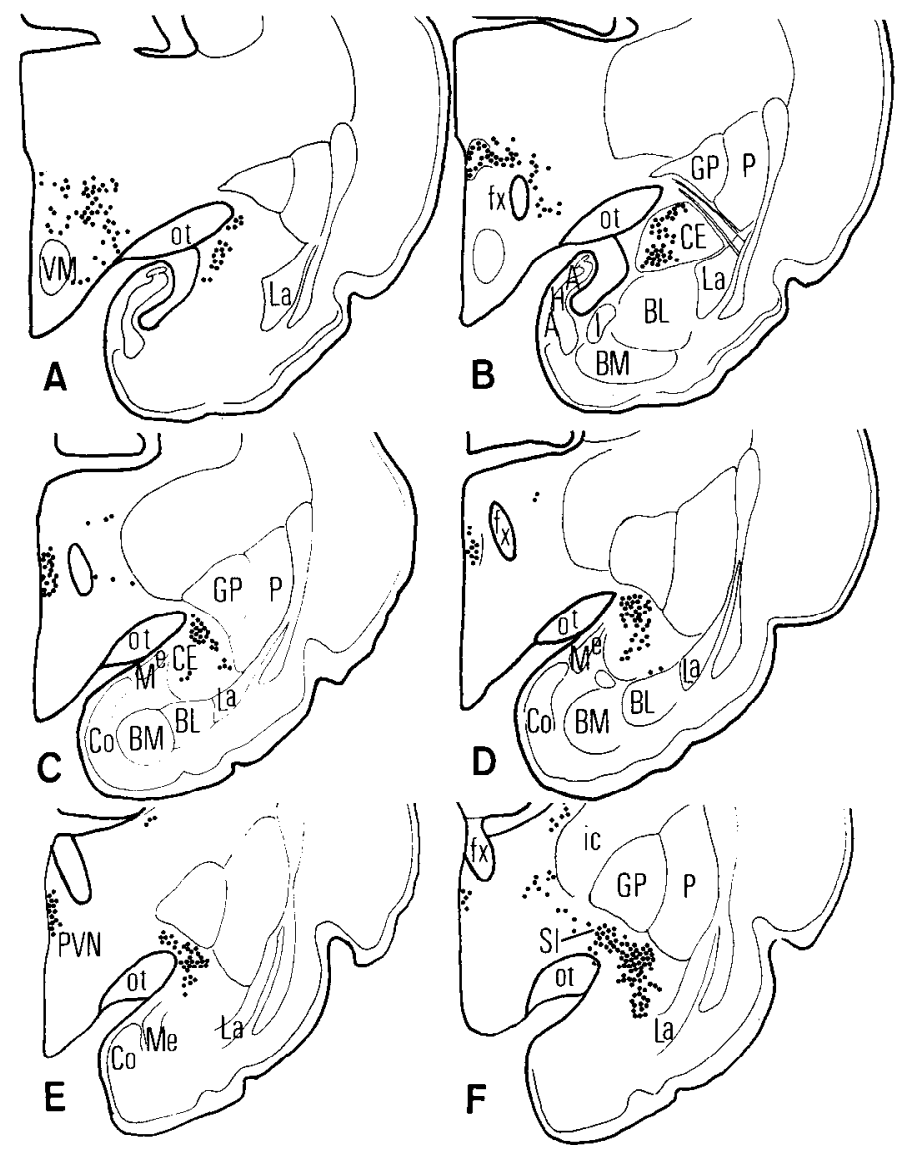

Figure 5. Line drawings of representative sections through the rabbit amygdala from case CN58 in which horseradish peroxidase was injected at multiple rostral-caudal levels in the dorsomedial medulla. The distribution of labeled neurons in the amygdala is plotted on sections from caudal $(A)$ to rostral $(F)$ levels. Each dot represents an individual labeled neuron from one section only. The region of the $C E$ containing labeled cells can be matched to the region of the $C E_{M}$ in Figures 1 to 3 and can be seen to be confined to and distributed throughout this subdivision. Notice the presence of cell labeling spilling beyond the dorsal border of the amygdala in $D$ to $F$. 
side of the cytoarchitectonic boundaries of the amygdala in the contiguous substantia innominata (Fig. 5, $D$ and $E$ ). The distribution of labeled cells appeared uninterrupted dorsomedially and continued to be present more rostrally within the substantia innominata, although at lower density (Fig. 6), remaining in association with the compact division of the longitudinal association bundle of Johnston. Labeled cells appeared to be largely confined within the cytoarchitectonic boundaries of only the sublenticular part of the substantia innominata and, particularly following large injections, to be fairly extensive throughout much of its area. Some labeled cells in the region ventral to the anterior commissure, however, tended to cluster medially and extend well into the diffuse border zone with the medial preoptic area or anterior hypothalamic area (Fig. 6).

The region of cell labeling was seen to expand and enlarge medially at levels just caudal to the anterior commissure, where the substantia innominata merges dorsomedially with the bed nucleus of the stria terminalis. Although the exact boundary between these structures is vague, labeled cells can be seen in Figure $6, B$ and $C$, to continue to be present beyond the diffuse border zone and extend into the bed nucleus. Within the
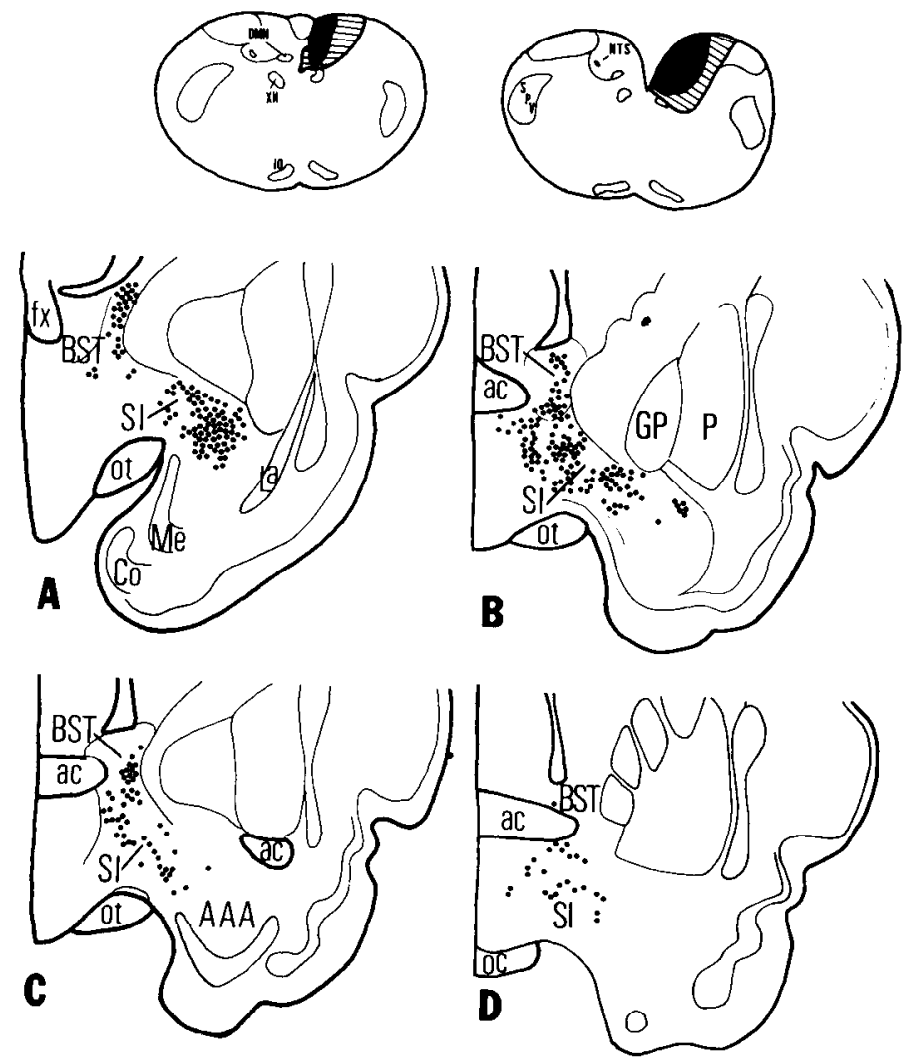

Figure 6. The location of retrogradely HRP-labeled cells from case CN58 plotted onto frontal sections at levels rostral to Figure 5 showing the distribution of cells within the substantia innominata $(S I)$ and bed nucleus of the stria terminalis (BST) from caudal $(A)$ to rostral $(D)$. The distribution of cells can be seen to form a continuum extending from the BST through the $S I$ into the $C E$ as a diagonal band. The top panel represents the injection site in this case. bed nucleus, labeling was confined to the lateral division. As illustrated in Figure $6, C$ and $D$, these lateral bed nucleus cells were concentrated lateral to the decussation of the anterior commissure and in a band in the lateral part of this division immediately adjacent to the internal capsule.

The regions of cell labeling across the central nucleus, substantia innominata, and bed nucleus were observed to be contiguous. Thus, the uninterrupted distribution of labeled cells across these three structures formed a diagonally extending continuum within the ventral forebrain. The labeled cells within this continuum appeared to be cytologically similar, consisting largely of medium sized, spindle-shaped or stellate neurons with two to four dendrites (Fig. 7). Morphometric analyses were performed in a few cases by drawing labeled cells with a drawing tube and measuring the drawn area with a digital image analyzer (Ladd). Morphometric analysis showed no significant difference in the average size of labeled cells in each of the three structures. It is interesting to note that, although the total number of retrogradely labeled cells varied across cases, labeling within the substantia innominata and bed nucleus appeared to remain proportionate, in considerably reduced number and density, to that in the central nucleus.

\section{Autoradiographic results}

Amygdala afferentation of the nucleus of the solitary tract and the dorsal motor nucleus. The innervation of the solitarius/vagal complex was examined in experiments in which injections of tritium-labeled amino acids were placed stereotaxically into amygdaloid and basal forebrain regions identified as containing efferent neurons by the HRP experiments. In 8 rabbits, injections were confined to the central nucleus; in 3 rabbits, one injection was confined to the central nucleus and a second injection was confined to the region of the border between the bed nucleus and the substantia innominata; and in 14 rabbits, injections at least partially involved one or more of these areas. The effective injection site was estimated to be of somewhat larger size than the central zone surrounding the needle track in which most cells appeared homogeneously blackened by the great density of overlying silver grains. In agreement with the results of the HRP experiments, which show that amygdaloid and basal ganglia structures surrounding the central nucleus do not project to the dorsomedial medulla, in those cases in which injections fell entirely outside of the central nucleus, bed nucleus, and substantia innominata, no transported label was observed in the dorsomedial medulla.

Following injections restricted to the central nucleus, labeled fibers stream rostrally, and the sublenticular substantia innominata and lateral part of the bed nucleus of the stria terminalis are heavily labeled. The compact division of the longitudinal association bundle of Johnston stands out as densely labeled fiber bundles coursing through this region (Fig. 8). Within the substantia innominata, the label is confined within the cytoarchitectonic boundaries of the sublenticular substantia innominata and appears to largely overlap the part of the region of 

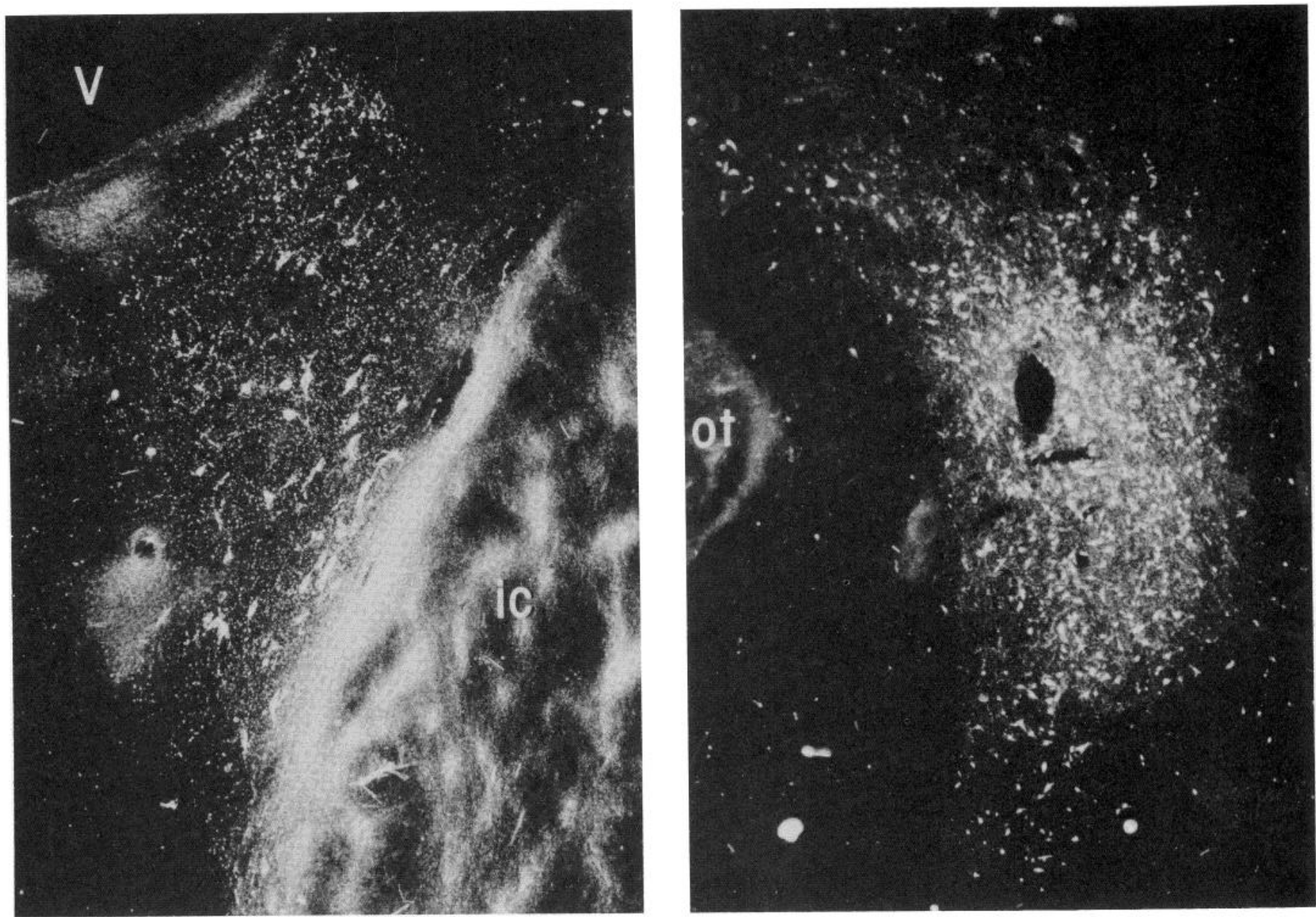

Figure 7. Dark-field, low power photomicrographs of frontal sections containing labeled cells in the lateral part of the bed nucleus of the stria terminalis (left panel) and in the medial subdivision of the central nucleus and the sublenticular substantia innominata (right panel) following the injection of $50 \mathrm{nl}$ of HRP into the NTS/DVN at $1.5 \mathrm{~mm}$ rostral, $0.1 \mathrm{~mm}$ rostral and $1 \mathrm{~mm}$ caudal to the obex.

the substantia innominata identified as containing efferent cells by the HRP experiments. Much of the label in this area can clearly be attributed to labeled fibers as indicated by linear rows of silver grains aligned parallel with the longitudinal association bundle. Silver grains, however, also are heavily distributed around many substantia innominata cells, suggesting a considerable amount of terminal labeling. Within the bed nucleus (Fig. $8 A$ ), transported label from the central nucleus is distributed throughout only the lateral subdivision and is particularly concentrated lateral to the decussation of the anterior commissure and in the lateral part of the lateral subdivision along the internal capsule, again in a pattern overlapping the area of retrograde labeling in the HRP experiments.

Labeled fibers from the central nucleus stream over the optic tract via the ventral amygdalofugal pathway at all rostral-caudal levels of the nucleus. At caudal levels, these fibers enter the lateral hypothalamus, where they are joined by fibers from the substantia innominata and the bed nucleus of the stria terminalis, and travel caudally through the lateral hypothalamus (Fig. $8 B$ ). Some central nucleus efferents also appear to travel in the stria terminalis and then pass through the bed nucleus and substantia innominata into the lateral preoptic/lateral hypothalamic areas. The course of the descending central nucleus pathway to the nucleus of the solitary tract and the dorsal motor nucleus probably is identified by the continuous transported label of apparent fibers through the brainstem. Caudal to the hypothalamus, labeled fibers continue into the tegmental area where they gradually become concentrated laterally as fascicles, initially, in the lateral part of the substantia nigra and then, in the pons, more dorsally on the medial border of the fifth nerve motor nucleus.

At the level of the medulla oblongata, transported label from the amygdala and basal forebrain is found in the ventrolateral reticular formation close to the surface of the brain at rostral levels and is distributed dorsomedially through the tegmental field to the nucleus of the solitary tract and the dorsal motor nucleus (Fig. 9). The density of label throughout the tegmentum is considerably lower than in the solitary tract and dorsal motor nuclei. In addition, many of the silver grains are arranged in linear 

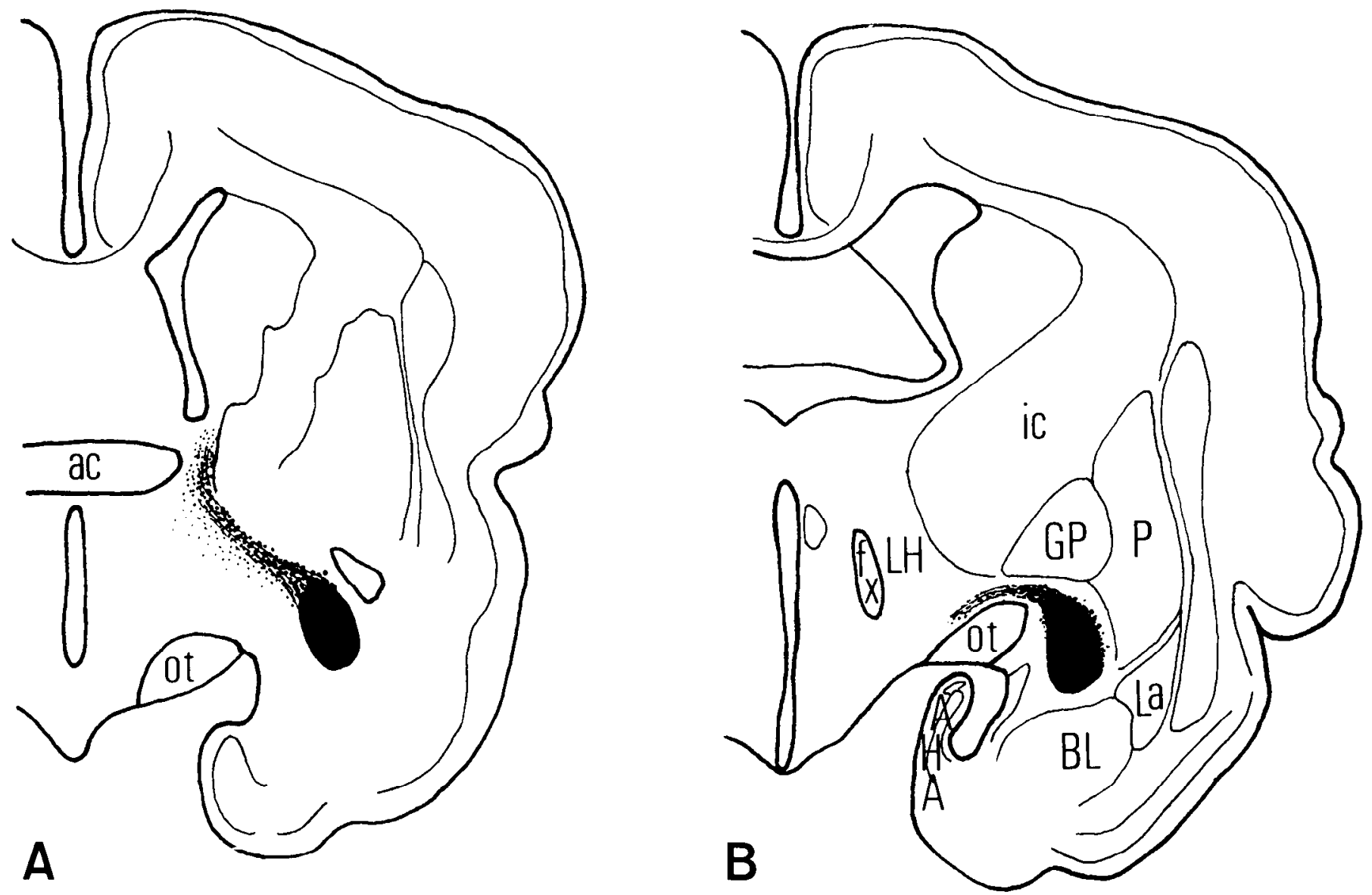

Figure 8. Projection drawing of sections through rostral $(A)$ and caudal $(B)$ levels of the central nucleus showing the localization of the injection site (100 nl of $\left[{ }^{3} \mathrm{H}\right]$ leucine $/\left[{ }^{3} \mathrm{H}\right]$ proline, $22.5 \mu \mathrm{Ci}$. 6-week exposure time) within the amygdala. In $A$, label can be seen to extend rostrally from the $C E_{M}$ into the $S I$ and lateral $B S T$, distributing throughout regions partially coextensive with the area delineated by the presence of HRP-labeled cells in Figures 5 and 6 . In $B$, label can be seen streaming dorsomedially out of the $C E$ over the optic tract.

"chains" oriented in a ventrolateral-to-dorsomedial direction, suggesting that the label is in fibers passing through this area rather than terminating within it. However, heavier label is distributed in the vicinity of the nucleus ambiguus at levels rostral to the obex, often appearing over nucleus ambiguus cells (Fig. 9). In the dorsomedial medulla, the density of grains increases, and heavy label extends medially around the border of the dorsal motor nucleus and is distributed within certain regions of the dorsal motor nucleus and the nucleus of the solitary tract.

At all rostrocaudal levels of the dorsal motor nucleus, label is found in the area around the nucleus and appears to encapsulate it (Figs. 10 and 11). At its rostral pole, considerable label also is distributed throughout the nucleus. Just caudal to its rostral pole, the dorsal motor nucleus in the rabbit may be divided into a larger celled dorsal subnucleus (a) and a smaller celled ventrally located subnucleus (b). At rostral levels, moderate-toheavy label is present within the dorsal motor nucleus within subnucleus a, but only light label is present in subnucleus b (Fig. 10). Caudal to the level of the obex, label is distributed only diffusely throughout the nucleus except, particularly caudal to the area postrema, where label is concentrated over a distinct group of cells lying in the border region between the dorsomedial aspect of the dorsal motor nucleus and the adjacent commissural and medial subnuclei of the nucleus tractus solitarius (Figs. 9 and 11). The cells are of a type that is intermediate in shape, staining properties, and size between those of the dorsal motor and solitary tract nuclei, but some of these cells appear to belong to the dorsal motor nucleus.

Within the nucleus of the solitary tract at rostral levels, heavy label is present in the lateral aspects of the nucleus, and moderate-to-heavy label is present more medially. At intermediate rostrocaudal levels, label is found within the dorsal and medial aspects of the medial subnucleus and also is found within the dorsomedial subnucleus bordering the dorsal column nuclei. Heavy label also is present in the ventral and ventrolateral subnuclei (Figs. 10 and 11). Caudal to the obex, label concentrates medially against the border of the nucleus tractus solitarius with the area postrema and also extends into the region of the commissural subnucleus (Fig. 11).

Differences did not appear to be prominent in the results following injections in the amygdala as opposed to injections in both the amygdala and bed nucleus/ substantia innominata. The direct comparison, however, 


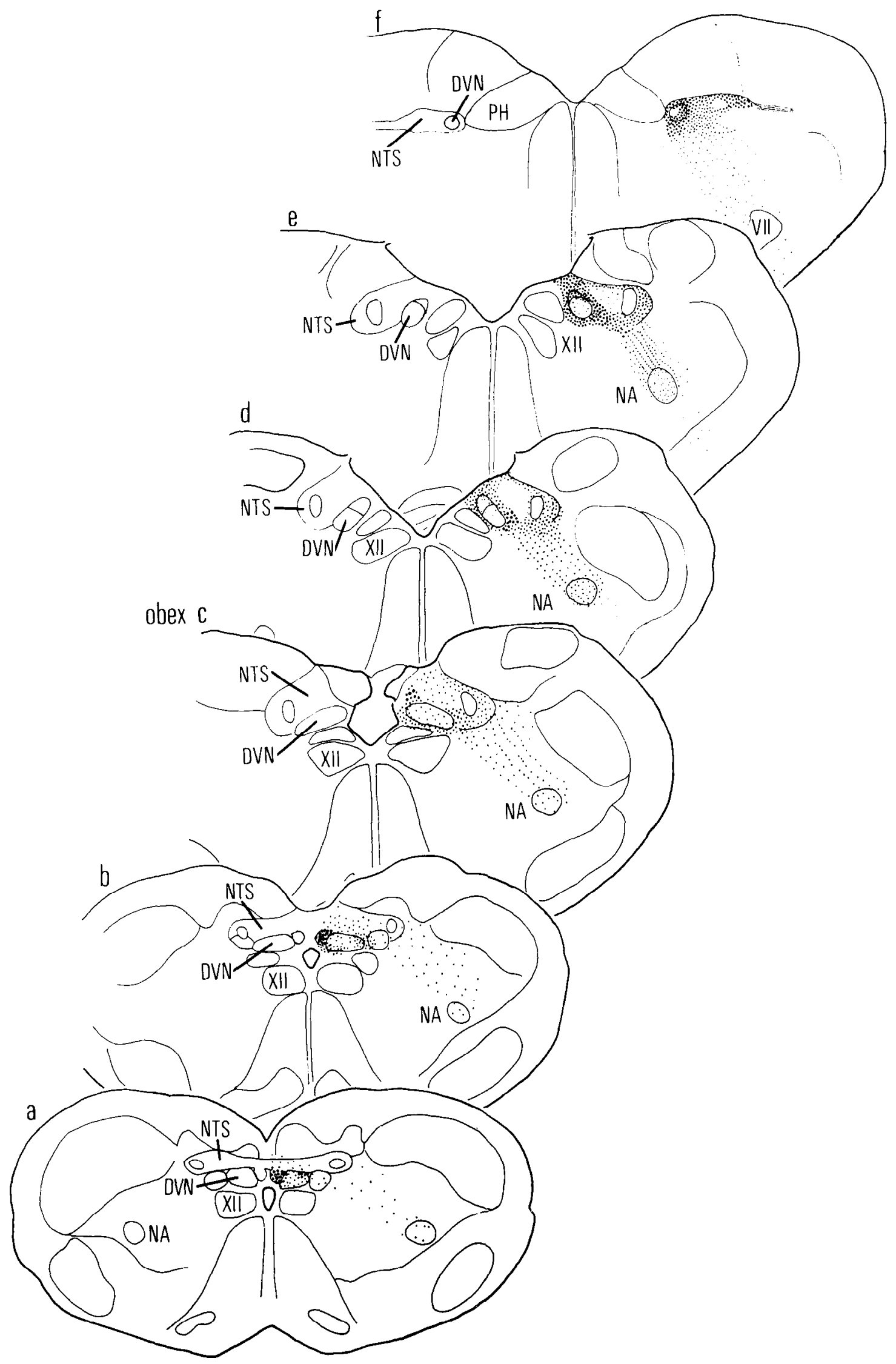

Figure 9. Schematic representation of the distribution of silver grains in the rabbit medulla visualized by autoradiography following the injection of $100 \mathrm{nl}$ of $\left[{ }^{3} \mathrm{H}\right]$ proline $/\left[{ }^{3} \mathrm{H}\right]$ leucine into the $C E$. Note the projections to the $N A, D V N$, and $N T S$ extending from rostral ( $e$ and $f$ ) to caudal $(a)$ levels of the nuclei. 

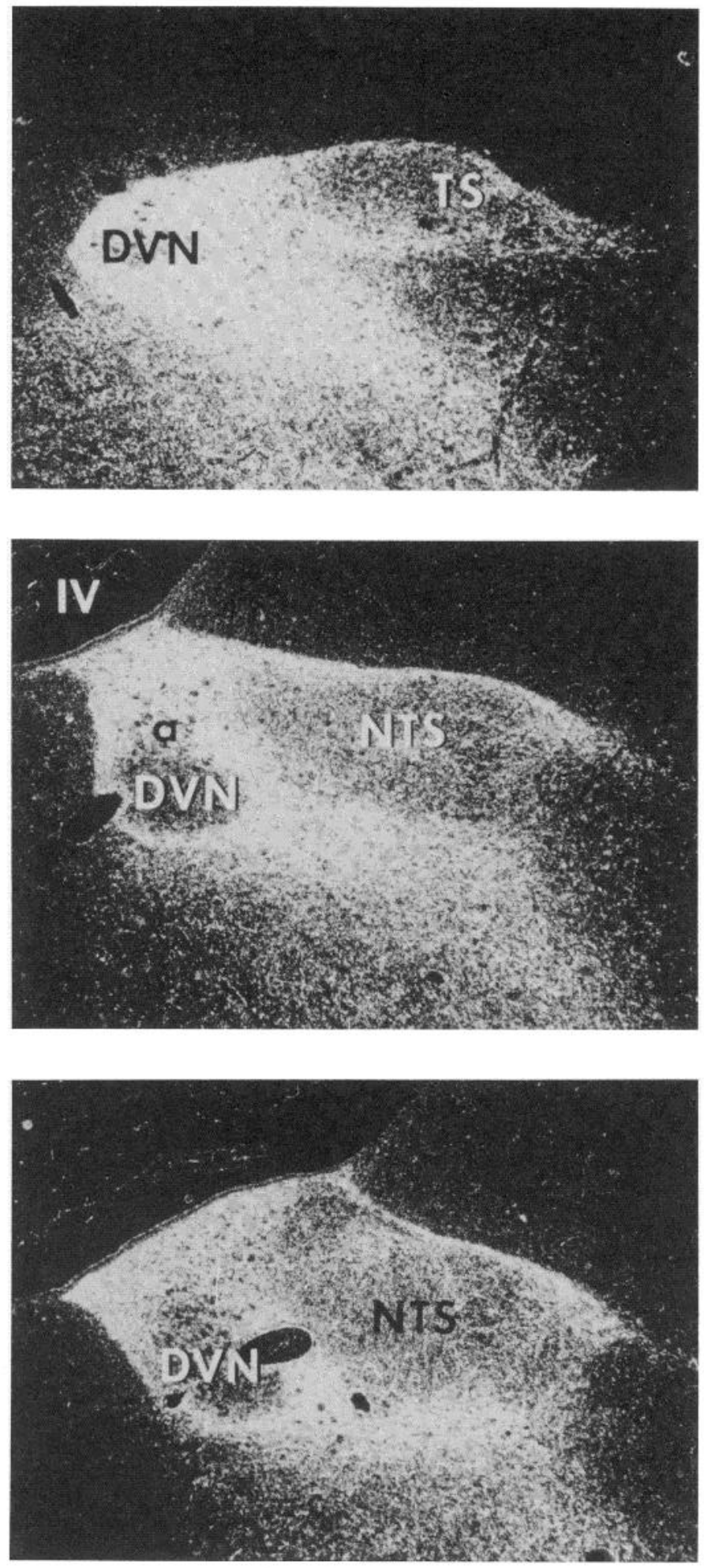

Figure 10. Dark-field photomicrographs of the dorsomedial medulla at the approximate levels of $f$ (top panel) to $d$ (bottom panel) in Figure 9 showing the distribution of silver grains within the $D V N$ and NTS following a 100 -nl injection of $\left[{ }^{3} \mathrm{H}\right]$ proline $/\left[{ }^{3} \mathrm{H}\right]$ leucine into the $C E$. Note the highly specific pattern of the projection to these nuclei, particularly to cell group $a$ of the $D V N$ and to the dorsomedial and ventral solitary tract nuclei.
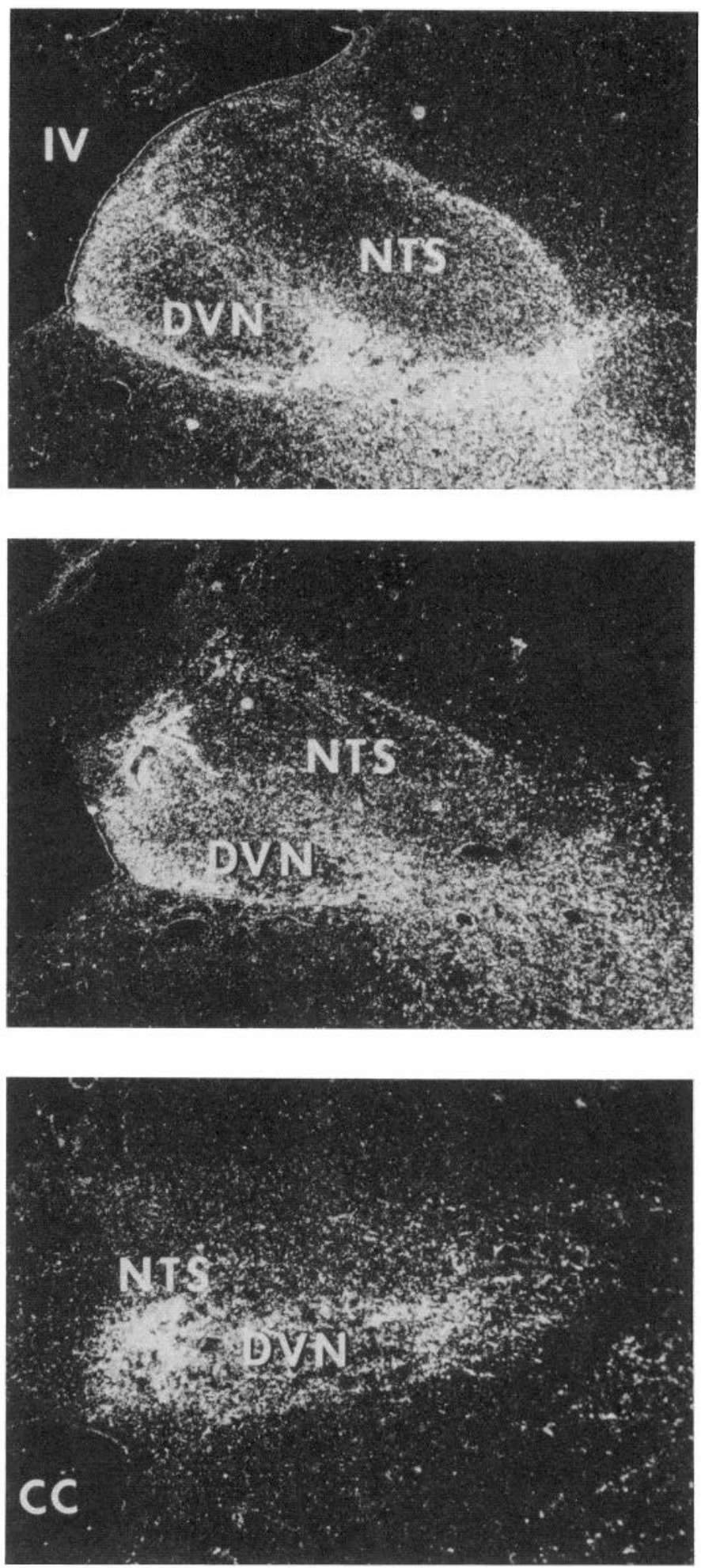

Figure 11. The distribution of transported label into the $D V N$ and NTS caudal to the level of Figure $9 d$. Note the concentration of label adjacent to the area postrema at the level of the obex (middle panel) and dorsomedially in the DVN caudal to the obex (bottom panel) and the absence of a significant amount of label in the central $D V N$ and the medial solitary tract nucleus. 
of the projection from the bed nucleus/substantia innominata versus that from the amygdala alone was not an objective of the present study and will be the subject of a subsequent paper.

\section{Discussion}

The present study examined the direct amygdaloid connections to the nucleus of the solitary tract and the dorsal motor nucleus. Experiments involving retrograde HRP transport, in conjunction with cytoarchitectonic descriptions, determined the full extent and distribution of the origin of this connection. They demonstrated that the population of amygdaloid efferent neurons was significantly large and restricted to the ipsilateral central nucleus of the amygdala. These experiments additionally demonstrated that the population of efferent neurons extends as a continuum well beyond the central nucleus into the substantia innominata and the bed nucleus of the stria terminalis, where it is distributed within certain subdivisions that may be closely associated with the central nucleus. Furthermore, experiments involving autoradiographic techniques demonstrated that the central nucleus heavily innervates the nucleus of the solitary tract, the dorsal motor nucleus, and the region of the nucleus ambiguus and that the connections to the former two structures selectively innervate discrete regions of each, some of which appear implicated in cardiovascular regulation.

Origin of the amygdaloid-dorsal medullary projection: Central nucleus. Prior to the present series of experiments, descending central nucleus connections to the nucleus of the solitary tract and dorsal motor nucleus had not been directly established. While it has long been recognized on the basis of important earlier degeneration studies that the amygdala gives rise to a major efferent outflow to the hypothalamus (Cowan et al., 1965; DeOlmos, 1972; DeOlmos and Ingram, 1972; Heimer and Nauta, 1969; Leonard and Scott, 1971), the continuation of this projection system into the brainstem has become apparent only by use of recently developed, more sensitive techniques for tracing axonal connections (Hopkins, 1975; Hopkins and Holstege, 1978; Krettek and Price, 1978b). However, in previous studies of descending amygdaloid projections using the autoradiographic technique, Krettek and Price (1978b) did not analyze the lower brainstem in their study of the rat and Hopkins and Holstege's (1978) study in the cat lacked injections limited to the central nucleus. Furthermore, HRP studies have not been made of retrograde transport from injections of the nucleus of the solitary tract and/or the dorsal motor nucleus.

The origin of the amygdaloid projection to the nucleus of the solitary tract and the dorsal motor nucleus was observed to be confined to, and distributed throughout, a medial subdivision of the ipsilateral central nuclcus, distinguishable on cytoarchitectonic grounds as a region of larger, more densely staining cells. Although this subdivision is located medially within the central nucleus, it occupies at least half of the area of the entire central nucleus and appears considerably larger than the thin medial strip usually described as constituting a medial subnucleus in the rat and cat (e.g., Brodal, 1947; Krettek and Price, 1978a; Wakefield and Hall, 1974). It should be noted, however, that, within the present medial subdivision in the rabbit, a smaller region of even larger and more darkly staining neurons can be distinguished. Thus, the central nucleus in the rabbit may consist of at least three divisions, and this dorsomedial region may constitute the classically defined medial subnucleus of the central nucleus. It is of interest that this smaller region within the present medial subdivision tends to contain labeled cells preferentially in cases with light labeling, possibly suggesting its more secure synaptic contact or greater neuronal activity with respect to the nucleus of the solitary tract and the dorsal motor nucleus. It is of interest that previous reports of central nucleus projections to the brainstem tegmentum in the cat, rat, and monkey also confined the origin of these projections to the medial central nucleus (Hopkins, 1975; Hopkins and Holstege, 1978). It is, however, unclear whether these projection neurons in these species are confined to the traditional, thin medial subdivision or to the larger region defined in the present study.

The present finding of a major direct central nucleus pathway to autonomic regulatory nuclei is consistent with other information implicating the central nucleus in autonomic regulation. In the rabbit, electrical stimulation within this nucleus produces profound bradycardia and depressor responses (Kapp et al., 1980), while lesions or chemical manipulations within the central nucleus impair conditioned heart rate responding (Kapp et al., 1978; Gallagher et al., 1980, 1981). In addition, recent anatomical studies indicate that the central nucleus is interconnected with other structures implicated in autonomic regulation. For example, the central nucleus gives rise to projections to the lateral hypothalamus (Hopkins and Holstege, 1978; Krettek and Price, 1978b) which, in turn, project to the nucleus of the solitary tract/dorsal motor nucleus (Saper et al., 1979; see also Fig. 5). Likewise, the central nucleus has been reported to receive afferents from both the nucleus of the solitary tract (Ricardo and Koh, 1978) and from the parabrachial nuclei of the pons (Norgren, 1978; Saper and Loewy, 1980). Thus, the present findings, together with other recent anatomical studies, indicate that the central nucleus may be the cephalic end of an "incestuously interconnected" sequence of structures extending rostrocaudally through the neuraxis to the nucleus of the solitary tract and dorsal motor nucleus.

Diagonal ventral forebrain continuum. An uninterrupted continuum of labeled cells extending through the medial subdivision of the central nucleus, sublenticular substantia innominata, and lateral part of the bed nucleus of the stria terminalis was observed following HRP injections into the nucleus tractus solitarius/dorsal motor nucleus. This diagonally extending band, as defined by the presence of efferents to autonomic regulatory structures, may suggest the anatomical unity of this band as a single entity. This possibility is supported by several observations of others. For example, the continuum delimited on the basis of efferent autonomic connectivity appears to be consistent with previous characterizations of the anatomical unity of these structures on the basis of common cytoarchitecture (Berkelbach van der Spren- 
kel, 1926; Heimer, 1978; Johnston, 1923) or staining properties (Novtony, 1977; DeOlmos, 1972). Likewise, many of these same regions have been identified in common as major forebrain sites of certain neurochemical systems, such as that of catecholamine innervation (Lindvall and Björklund, 1974; Swanson and Hartman, 1975) or neuropeptide innervation (Ben-Ari et al., 1976; Schwaber et al., 1981; Wray et al., 1981). In addition, certain connectional and neurophysiological evidence also indicates a possible functional commonality within this diagonal efferent band with respect to autonomic or visceral function. For example, the entire region appears to be the recipient of visceral afferents both directly from the nucleus tractus solitarius (Ricardo and Koh, 1978) and via a relay in the parabrachial nucleus of the pons (Norgren, 1978). Furthermore, it should be noted that, in addition to the central nucleus, electrical stimulation also has been reported to produce cardiovascular effects in the region laterally bordering the decussation of the anterior commissure (Hilton and Spyer, 1971; Kabat et al., 1935), a region defined in the present study as the lateral part of the bed nucleus and which forms part of the present diagonal band.

Terminal distribution of amygdaloid-dorsal medullary projections. The autoradiographic findings are of particular interest in that the labeling representing descending central nucleus projections was not distributed homogeneously throughout either the nucleus of the solitary tract or the dorsal motor nucleus, but rather, only certain regions of each nucleus were heavily labeled. Since both of these nuclei show substantial cytoarchitectonic subdivision which may be correlated with the multiple functions subserved by each (Higgins and Schwaber, 1981; Loewy and Burton, 1978), the pattern of descending central nucleus input to each nucleus may suggest the possible functional roles of the pathway. For example, within the nucleus of the solitary tract, the pattern of regional labeling appeared to respect the boundaries of certain subnuclei associated with cardiovascular regulation. Thus, at intermediate rostrocaudal levels of the nucleus, the autoradiographic label that is concentrated over a dorsomedial strip within the nucleus occupies the region of the cytoarchitectonically distinct dorsomedial subnucleus in the rabbit (Higgins and Schwaber, 1981) and thus appears to be coextensive with the region receiving afferentation by the aortic depressor nerve in the rabbit (Higgins and Schwaber, 1981). Since the aortic nerve exclusively contains baroreceptor afferents, this connectivity suggests a role in the baroreceptor reflex or other cardiovascular regulation for the descending projections to this region. Since stimulation of the central nucleus in the rabbit produces an immediate, profound bradycardia in the rabbit (Kapp et al., 1980), it may be suggested speculatively that these central nucleus inputs to the dorsomedial subdivision act to facilitate baroreceptor reflexes. In addition, further cardiovascular influences may be mediated by the descending projections indicated by label concentrated overlying the ventrolateral subnuclei of the rabbit nucleus tractus solitarius. The ventrolateral subnucleus is the area of the respiratory "dorsal respiratory group" (Cohen, 1979; von Euler et al., 1973) and central nucleus projections to this region may influence cardiovascular activity secondarily via respiration-locked effects on vagal cardiac neurons (McAllen et al., 1979).

In the case of the dorsal motor nucleus, terminal labeling within this nucleus is moderate to heavy at rostral levels only in the large celled part of the nucleus that we have designated subnucleus a and caudally in the distinct dorsomedial cell group which appears to belong to the dorsal motor nucleus. Since the dorsal motor nucleus possesses some "viscerotopic" as well as a subnuclear organization (e.g., Getz and Sirnes, 1949; MacDonald and Cohen, 1973; Mitchell and Warwick, 1955; Schwaber and Cohen, 1978), it is possible that this regional innervation reflects some specific functional subdivision of the innervation of the nucleus. Heavy label also was observed in the vicinity of the nucleus ambiguus cells. Since the nucleus ambiguus, as well as the dorsal motor nucleus, gives rise to vagal efferents to the heart (e.g., McAllen and Spyer, 1976; Schwaber et al., 1979) as well as to other visceral organs (J. S. Schwaber unpublished observations), the amygdaloid connections to this nucleus also may influence cardiovascular and other autonomic function.

Possible significance of the present findings. The central nucleus of the amygdala and the bed nucleus of the stria terminalis have been implicated in the expression of autonomic as well as somatomotor components of emotional behaviors in the cat (Heinemann et al., 1973; Hilton and Zbrozyna, 1963; Roldan et al., 1974; Stock et al., 1978). In the rabbit, recent research also has implicated the central nucleus in the expression of heart rate responses to conditioned fear stimuli (Kapp et al., 1978, 1979; Gallagher et al., 1980, 1981). Since this conditioned heart rate response in the rabbit is mediated primarily by the vagus nerve (Fredericks et al., 1974), the present findings of a direct projection from the central nucleus to the nucleus of the solitary tract, dorsal motor nucleus of the vagus, and nucleus ambigius lend further evidence in support of a role for the central nucleus in cardiovascular components of emotional behavior. Furthermore, it is not unreasonable to assume that the direct central nucleus pathway could contribute to the vagally mediated conditioned heart rate response by directly influencing cardioinhibitory motoneurons in the nucleus ambiguus and the dorsal motor nucleus (Schwaber and Schneiderman, 1975) or by indirectly influencing vagal cardioinhibitory motoneurons via the baroreceptor reflex neuronal populations within the nucleus of the solitary tract.

\section{References}

Beckstead, R. M., and R. Norgren (1979) An autoradiographic examination of the central distribution of the trigeminal, facial, glossopharyngeal, and vagal nerves in the monkey. J. Comp. Neurol. 184: 455-472.

Ben-Ari, Y., I. Kanazawa, and R. E. Zigmond (1976) Regional distribution of glutamate decarboxylase within the amygdaloid complex and stria terminalis system of the rat. J. Neurochem. 26: 1279-1283.

Berkelbach van der Sprenkel, H. (1926) Stria terminalis and amygdala in the brain of the opossum (Didelphis virginiana). J. Comp. Neurol. 42: 211-254.

Biscoe, T., and S. Sampson (1970) Responses of cells in the brain stem of the cat to stimulation of the sinus, glossopha- 
ryngeal, aortic, and superior laryngeal nerves. J. Physiol. (Lond.) 209: 359-373.

Bodian, D. (1937) An experimental study of the optic tracts and retinal projection of the Virginia opossum. J. Comp. Neurol. 66: $113-144$.

Brodal, A. (1947) The amygdaloid nucleus in the rat. J. Comp. Neurol. 87: 1-16.

Cohen, D. H., and A. M. Schnall (1970) Medullary cells of origin of vagal cardioinhibitory fibers in the pigeon. II. Electrical stimulation of the dorsal motor nucleus. J. Comp. Neurol. 140: 321-342.

Cohen, M. I. (1979) Neurogenesis of respiratory rhythm in the mammal. Physiol. Rev. 89: 1105-1173.

Cowan, W. M., G. Raisman, and T. P. S. Powell (1965) The connections of the amygdala. J. Neurol. Neurosurg. Psychiatry 28: $137-151$.

DeOlmos, J. S. (1972) The amygdaloid projection field in the rat as studied with the cupric-silver method. In The Neurobiology of the Amygdala, B. E. Eleftheriou, ed., pp. 145-204, Plenum Press, New York.

DeOlmos, J. S., and W. R. Ingram (1972) The projection field of the stria terminalis in the rat brain. An experimental study. J. Comp. Neurol. 146: 303-334.

Fox, C. A. (1940) Certain basal telencephalic centers in the cat. J. Comp. Neurol. 72: 1.

Fredericks, A., J. W. Moore, F. V. Metcalf, J. S. Schwaber, and N. Schneiderman (1974) Selective autonomic blockade of conditioned and unconditioned heart rate changes in rabbits. Pharmacol. Biochem. Behav. 2: 493-501.

Gallagher, M., B. S. Kapp, K. Frysinger, and P. Rapp (1980) $\beta$-Adrenergic manipulation in the amygdala central nucleus alters rabbit heart rate conditioning. Pharmacol. Biochem. Behav. 12: 419-426.

Gallagher, M., B. S. Kapp, C. L. McNall, and J. P. Pascoe (1981) Opiate effects in the amygdala central nucleus on heart rate conditioning in rabbits. Pharmacol. Biochem. Behav. 14: 497-505.

Getz, G., and T. Sirnes (1949) The localization within the dorsal motor nucleus. J. Comp. Neurol. 90: 95-110.

Gurdjian, E. A. (1928) The corpus striatum of the rat. Studies on the brain of the rat, No. 3. J. Comp. Neurol. 45: 249-281.

Heimer, L. (1978) The olfactory cortex and the ventral striatum. In Limbic Mechanisms, K. Livingston and O. Hornykiewics, eds., pp. 95-187, Plenum Press, New York.

Heimer, L., and W. J. H. Nauta (1969) The hypothalamic distribution of the stria terminalis in the rat. Brain Res. 13: 284-297.

Heinemann, H., G. Stock, and H. Schaeffer (1973) Temporal correlation of responses in blood pressure and motor reaction under electrical stimulation of limbic structures in the unanesthetized unrestrained cat. Pflugers Arch. 343: 27-40.

Higgins, G. A., and J. S. Schwaber (1981) Afferent organization of the nucleus tractus solitarius of the rabbit: Evidence for overlap of forebrain and primary afferent inputs. Anat. Rec. 199: 114A.

Hilton, S. M., and K. M. Spyer (1971) Participation of the anterior hypothalamus in the baroreceptor reflex. J. Physiol. (Lond.) 218: 271-293.

Hilton, S. M., and A. W. Zbrozyna (1963) Amygdaloid region for defense reactions and its efferent pathway to the brain stem. J. Physiol. (Lond.) 156: 160-173.

Hopkins, D. A. (1975) Amygdalotegmental projections in the rat, cat and rhesus monkey. Neurosci. Lett. 1: 263-270.

Hopkins, D. A., and G. Holstege (1978) Amygdaloid projections to the mesencephalon, pons and medulla oblongata in the cat. Exp. Brain Res. 32: 529-547.

Humphrey, D. R. (1967) Neuronal activity in the medulla oblongata of the cat evoked by stimulation of the carotid sinus nerve. In Baroreceptors and Hypertension, P. Kezdi, ed., pp. 131-169, Pergamon Press, Oxford.

Johnston, J. B. (1923) Further contributions to the study of the evolution of the forebrain. J. Comp. Neurol. 35: 337-481.

Jones, E. G., H. Burton, C. B. Saper, and L. W. Swanson (1976) Midbrain, diencephalic and cortical relationships of the basal nucleus of Meynert and associated structures in primates. J. Comp. Neurol. 167: 385-420.

Jordan, D., and K. M. Spyer (1977) Studies on the termination of sinus nerve afferents. Pflugers Arch. 369: 65-73.

Kabat, H., H. W. Magoun, and S. W. Ranson (1935) Electrical stimulation of points in the forebrain and midbrain. Arch. Neurol. Psychiatry 34: 931-952.

Kalia, M., and M. M. Mesulam (1980) Brain stem projections of afferent and efferent fibers in the cat: II. Laryngeal tracheobronchial, pulmonary, cardiac and gastrointestinal branches. J. Comp. Neurol. 193: 523-553.

Kapp, B. S., R. C. Frysinger, M. Gallagher, and J. S. Schwaber (1978) The central nucleus of the amygdala: Bulbar projection and involvement in heart rate conditioning. Soc. Neurosci. Abstr. 4: 809 .

Kapp, B. S., R. C. Frysinger, M. Gallagher, and J. R. Hazelton (1979) Amygdala central nucleus lesions: Effect on heart rate conditioning in the rabbit. Physiol. Behav. 23: 1109-1117.

Kapp, B. S., M. Gallagher, M. D. Underwood, C. L. McNall, and D. Whitehorn (1980) Cardiovascular responses produced by stimulation of amygdala central nucleus. Soc. Neurosci. Abstr. 6: 817.

Klüver, H., and E. Barrera (1953) A method for the combined staining of cells and fibers in the nervous system. J. Neuropathol. Exp. Neurol. 12: 400-403.

Krettek, J. E., and J. T. Price (1978a) Amygdaloid projections to subcortical structures within the basal forebrain and brainstem in rat and cat. J. Comp. Neurol. 178: 225-254.

Krettek, J. E., and J. L. Price (1978b) A description of the amygdaloid complex in the rat and cat with observations on intra-amygdaloid axonal connections. J. Comp. Neurol. 178: 225-280.

Leonard C. M., and J. W. Scott (1971) Origin and distribution of the amygdalofugal pathways in the rat: An experimental neuroanatomical study. J. Comp. Neurol. 141: 313-330.

Lindvall, O., and A. Björklund (1974) The organization of the ascending catecholamine neuron systems in the rat brain as revealed by the glyoxylic acid fluorescence method. Acta Physiol. Scand. Suppl. 412: 1-48.

Loewy, A. D., and H. Burton (1978) Nuclei of the solitary tract: Efferent projections to the lower brain stem and spinal cord of the cat. J. Comp. Neurol. 181: 421-450.

MacDonald, R. L., and D. H. Cohen (1973) Heart rate and blood pressure responses to electrical stimulation of the central nervous system in the pigeon (Columbia livia). J. Comp. Neurol. 150: 109-136.

McAllen, R. M., and K. M. Spyer (1976) The location of cardiac vagal preganglionic motoneurons in the medulla of the cat. J. Physiol. (Lond.) 258: 187-204.

McAllen, R. M., D. Jordan, and K. M. Spyer (1979) The carotid baroreceptor input to the brain. In Central Interactions between Respiratory and Cardiovascular Control Systems, H. P. Koepchen, S. M. Hilton, and K. M. Spyer, eds., pp. 8792, Springer, Berlin.

Miodonsky, R. (1967) Myeloarchitectonics and connections of substantia innominata in the dog brain. Acta Biol. Exp. (Warsaw) 27:61-84.

Mitchell, G. A. G., and R. Warwick (1955) The dorsal vagal nucleus. Acta Anat. (Basel) 25: 317-395.

Miura, M., and D. Reis (1969) Termination and secondary projections of carotid sinus nerve in the cat brain stem. Am. J. Physiol. 217: 142-153. 
Mogenson, G. J., and R. F. Calaresu (1973) Cardiovascular responses to electrical stimulation of the amygdala in the rat. Exp. Neurol. 39: 166-180.

Norgren, R. (1978) Projection from the nucleus of the solitary tract in the rat. Neuroscience 3: 207-218.

Novotny, G. E. K. (1977) A direct ventral connection between the bed nucleus of the stria terminalis and the amygdaloid complex in the monkey (Macaca fascicularis). J. Hirnforsch. 18: 271-284.

Ricardo, J. A., and E. T. Koh (1978) Anatomical evidence of direct projection from the nucleus of the solitary tract to the hypothalamus, amygdala, and forebrain structures in the rat. Brain res. 153: 1-26.

Roldan, E., R. Alvanez-Pelaez, and A. F. deMolina (1974) Electrographic study of the amygdaloid defense response. Physiol. Behav. 13: 779-787.

Saper, C. B., and A. D. Loewy (1980) Efferent connections of the parabrachial nucleus in the rat. Brain Res. 197: 291-317.

Saper, C. B., L. W. Swanson, and W. M. Cowan (1979) An autoradiographic study of the efferent connections of the lateral hypothalamic area in the rat. J. Comp. Neurol. 182: 689-706.

Schwaber, J. S., and D. H. Cohen (1978) Field potential and single unit analysis of the avian dorsal motor nucleus of the vagus and criteria for identifying vagal cardiac cells of origin. Brain Res. 147: 79-90.

Schwaber, J. S., and N. Schneiderman (1975) Aortic nerve activated cardioinhibitory neurons and interneurons. Am. J. Physiol. 299: 783-790.

Schwaber, J. S., S. Wray, and G. A. Higgins (1979) Vagal cardiac innervation: Contributions of the dorsal motor nucleus and the nucleus ambiguus determined by liquid scintillation counting. Soc. Neurosci. Abstr. 4: 809.
Schwaber, J. S., B. S. Kapp, and G. A. Higgins (1980) The origin and extent of direct amygdala projections to the region of the dorsal motor nucleus of the vagus and the nucleus of the solitary tract. Neurosci. Lett. 20: 15-20.

Schwaber, J. S., S. Wray, G. A. Higgins, and G. Hoffman (1981) The central nucleus of the amygdala: Descending autonomic connections and neuropeptide systems in the rat. Anat. Rec. 199: 228A.

Stock, G., Y. Schlör, H. Heidt, and J. Russ (1978) Psychomotor behavior and cardiovascular patterns during stimulation of the amygdala. Pflugers Arch. 376: 177-184.

Swanson, L. W. (1976) The locus coeruleus: A cytoarchitectonic, Golgi and immunohistochemical study in the albino rat. Brain Res. 110: 39-56.

Swanson, L. W., and B. K. Hartman (1975) The central adrenergic system. An immunofluorescence study of the location of cell bodies and their efferent connections in the rat utilizing dopamine-beta-hydroxylase as a marker. J. Comp. Neurol. 163: 467-506.

von Euler, C., J. N. Hayward, I. Martilla, and R. J. Wyman (1973) Respiratory neurons of the ventrolateral solitary tract to the cat: Vagal input, spinal connections and morphological identification. Brain Res. 61: 1-22.

Wakefield, C., and E. Hall (1974) Some observations of the central amygdaloid nucleus in the cat. Cell Tissue Res. 651: $489-498$.

Wray, S., J. S. Schwaber, and G. Hoffman (1981) Neuropeptide localization in the rat central amygdaloid nucleus. Anat. Rec. 199: 282A.

Young, M. W. (1936) The nucleus pattern and fiber connections of the noncortical centers of the telencephalon of the rabbit (Lepus cuniculus). J. Comp. Neurol. 65: 295-380. 